\title{
Outbreaks attributed to pork in the United States, 1998-2015
}

\author{
J. L. SELF ${ }^{1,2}$, R. E. LUNA-GIERKE ${ }^{2}$, A. FOTHERGILL ${ }^{3}$, K. G. HOLT ${ }^{4}$ AND \\ A. R. VIEIRA ${ }^{2}$ \\ ${ }^{1}$ Epidemic Intelligence Service, Division of Scientific Education and Professional Development, CSELS, Centers \\ for Disease Control and Prevention, Atlanta, GA, USA \\ ${ }^{2}$ Enteric Diseases Epidemiology Branch, Division of Foodborne, Waterborne, and Environmental Diseases, \\ NCEZID, Centers for Disease Control and Prevention, Atlanta, GA, USA \\ ${ }^{3}$ Department of Epidemiology, Rollins School of Public Health, Emory University, Atlanta, GA, USA \\ ${ }^{4}$ Food Safety and Inspection Service, United States Department of Agriculture, Atlanta, GA, USA
}

Received 2 May 2017; Final revision 18 August 2017; Accepted 21 August 2017; first published online 14 September 2017

\section{SUMMARY}

Each year in the United States, an estimated 525000 infections, 2900 hospitalizations, and 82 deaths are attributed to consumption of pork. We analyzed the epidemiology of outbreaks attributed to pork in the United States reported to the Centers for Disease Control and Prevention (CDC) 1998-2015. During that period, 288 outbreaks were attributed to pork, resulting in 6372 illnesses, 443 hospitalizations, and four deaths. The frequency of outbreaks attributed to pork decreased by $37 \%$ during this period, consistent with a decline in total foodborne outbreaks.

However, outbreaks attributed to pork increased by $73 \%$ in 2015 (19 outbreaks) compared with the previous 3 years (average of 11 outbreaks per year), without a similar increase in total foodborne outbreaks. Most ( $>99 \%$ ) of these outbreaks occurred among people exposed in the same state. The most frequent etiology shifted from Staphylococcus aureus toxin during 1998-2001 (19\%) to Salmonella during 2012-2015 (46\%). Outbreaks associated with ham decreased from eight outbreaks per year during 1998-2001, to one per year during 2012-2015 $(P<0 \cdot 01)$. Additional efforts are necessary to reduce outbreaks and sporadic illnesses associated with pork products.

Key words: Enteric bacteria, foodborne infections, food safety.

\section{INTRODUCTION}

Swine can carry human pathogens [1-3], and pork products may become contaminated during and after slaughter. The Centers for Disease Control and Prevention (CDC) has estimated that consumption of pork is responsible for 525000 foodborne infections, 2900 hospitalizations, and 82 deaths each

\footnotetext{
* Author for correspondence: Dr J. L. Self, 1600 Clifton Road NE, MS-A38, Atlanta, GA 30329, USA.

(Email: yxj9@cdc.gov)
}

year [4]. Several recent pork-associated outbreaks highlight the risks associated with this food $[5,6]$.

Trichinella and Yersinia enterocolitica ( $Y$. enterocolitica) have historically been important human pathogens associated with pork [7, 8]. Cases of trichinellosis, caused by the parasite Trichinella found in undercooked pork [9], have declined since 1950, primarily due to changes in production practices and possibly aided by consumer education; outbreaks are now rare in the United States [10]. Outbreaks and sporadic cases of yersiniosis have been associated with household exposure to chitterlings, commonly called 
'chitlins', which are made from swine intestines [11-13]. $Y$. enterocolitica infections have declined significantly since 1996, possibly due to changes in slaughtering practices and educational campaigns, but there are continuing risks for infection, especially among children in settings where chitterlings are being prepared [13-15].

In spite of these achievements, foodborne illnesses and outbreaks attributed to pork still cause substantial morbidity and mortality in the United States and have not been previously summarized [4]. This report summarizes the epidemiological characteristics of outbreaks attributed to pork in the United States and its territories during 1998-2015.

\section{METHODS}

\section{Surveillance data}

CDC has conducted surveillance for foodborne disease outbreaks in the United States through the Foodborne Disease Outbreak Surveillance System (FDOSS) since 1973. A foodborne disease outbreak is defined as two or more cases of a similar illness resulting from ingestion of a common food [16]. Public health agencies in all 50 states, the District of Columbia, US territories, and Freely Associated States (Micronesia, Marshall Islands, and Palau) identify and investigate outbreaks and report them to FDOSS using a standard form. Electronic reporting to FDOSS began in 1998, and a web-based platform was introduced in 2009 .

The information collected in the outbreak report includes etiology (causative bacteria, chemicals or toxins, viruses, and/or parasites), month, year, and state in which the outbreak occurred, number of illnesses, hospitalizations, deaths that resulted from becoming ill during the outbreak, implicated food(s), locations where food was prepared and consumed, and factors that contributed to the outbreak. Health agencies may implicate food vehicles using a combination of epidemiologic, laboratory, or traceback/environmental evidence, and exercising judgment about the strength of the evidence. CDC provides standard guidance, but methods vary by jurisdiction [17]. Outbreaks may be reported without implicating a vehicle. Outbreaks in which the implicated food was pork or a food where the contaminated ingredient was identified as pork were selected for this analysis, and data were extracted from the FDOSS database on 28 June 2016.

To compare changes over time in pork outbreaks with pork consumption rates, pork disappearance data were obtained from the Economic Research
Service of the United States Department of Agriculture (USDA) [18]. Food disappearance is a proxy for annual consumption of a particular food derived from information on total production of the food item, imports, and beginning stocks of commodities, less any exports, ending stocks, and non-food uses [19].

\section{Analyses}

Outbreaks were classified by year and season based on the illness onset date for the first case. Winter was considered December, January, and February; Spring was March to May; Summer June to August; and Fall September to November.

Health agencies follow standard guidance to report the etiology of an outbreak. The criteria for reporting an etiology as confirmed varies by etiology but generally requires isolation of the pathogen from clinical specimens of two or more people or from an epidemiologically implicated food [20]. Outbreaks that do not meet guidelines for a confirmed etiology may be reported with a suspected etiology based on clinical symptoms or epidemiologic experience. Outbreaks may be reported with an unknown etiology, and multiple etiologies may be reported. Etiologies for each outbreak are classified as bacterial, viral, parasitic, or chemical/toxin and identified by species and subtype, where appropriate $[17,20]$.

Implicated foods or contaminated ingredients that were pork or contained pork were categorized as follows: barbecue pork (e.g. pulled pork, pig roasts, carnitas), pork entrées (e.g. chops, tenderloins, ribs), ham, processed pork (e.g. canned pork products, sausage, bacon), pork by-products (e.g. feet, head, chitterlings), and other pork. Outbreaks attributed to foods in the 'other' category were typically multiple-ingredient foods (e.g. pork fried rice, soup containing pork). Although ham is a processed food, it was analyzed separately due to the large number of associated outbreaks.

If consumption of the contaminated food occurred in a single state, the outbreak was considered a singlestate outbreak, irrespective of ill persons' residence. Multistate outbreaks were considered those in which contaminated food was consumed in more than one state. Outbreaks with a single location where food was prepared were categorized as follows: restaurant (sit-down dining, fast food, or other), catering or banquet facility, other commercial location (grocery, convenience store, fair, festival, or other temporary or mobile service), institutional location (school, work, 
camp, day care, hospital, workplace), religious facility, private home, and other. Outbreaks with more than one preparation location reported were classified into the same category if all of the preparation locations fell within one category; otherwise they were classified as 'multiple'.

The standard outbreak reporting form allows health agencies to identify factors that contributed to the outbreak, and multiple contributing factors can be reported for each outbreak. For simplicity, contributing factors were categorized as either improper food preparation (e.g. cross-contamination of ingredients, improper temperature control, and insufficient time and/or temperature during cooking), contamination due to poor food handler hygiene, outside contamination (contamination due to factors outside of the location of preparation), or other [21, 22].

Analyses included all years of available data after electronic reporting was introduced (1998-2015) except when assessing changes over time. Changes over time were assessed by comparing the first 4 years of available data (1998-2001) with the most recent 4 years of available data (2012-2015). Statistical significance was assessed using Student's $t$ test. Statistical analyses were conducted in SAS v. $9 \cdot 4$ (SAS Institute Inc., USA).

\section{RESULTS}

During 1998-2015, there were 288 outbreaks attributed to pork, resulting in 6372 illnesses, 443 hospitalizations, and four deaths (Table 1). The median number of outbreaks per year was 16.5 (range 10-25), and the median number of illnesses per outbreak was 12 (range 2-333).

\section{Changes in reported outbreaks and pork consumption}

The frequency of outbreaks attributed to pork decreased 37\%, from 21 per year during 1998-2001 to 13 during 2012-2015 ( $P=0 \cdot 03$, Table 2). Similarly, the total number of reported foodborne outbreaks from any source decreased 35\%, from 1327 per year during 1998-2001 to 858 per year during 2012-2015 $(P<0 \cdot 01)$ (Fig. 1). However, 19 outbreaks were attributed to pork in 2015 , a $73 \%$ increase compared with the average of 11 per year during the previous 3 years, while the total number of foodborne outbreaks increased only a small amount during the same period ( $7 \%$ increase). In addition, the number of pork outbreak-associated illnesses increased $11 \%$, from 432 per year during 1998-
2001 to 478 per year during 2012-2015 (Fig. 1), while per capita pork consumption decreased $8 \%$, from 52 pounds per year during $1998-2001$ to 47 pounds per year during $2012-2015(P<0 \cdot 01)$.

The season with the highest number of outbreaks was Summer (84, 29\% of pork outbreaks) accounting for 1907 (30\%) illnesses, followed by Fall (82, 28\% of pork outbreaks) accounting for 1913 (30\%) illnesses, and Spring $(67,23 \%$ of pork outbreaks) accounting for 1883 illnesses. Winter accounted for the lowest number of outbreaks and illnesses: $55(19 \%)$ and 669 $(10 \%)$, respectively.

\section{Geographical distribution of outbreaks}

Forty-two states plus Puerto Rico and the US Virgin Islands reported at least one outbreak attributed to pork. The states reporting the largest number of single-state outbreaks were Florida (43, $15 \%$ of singlestate outbreaks) and California (24, 8\%) (Fig. 2). Two multistate outbreaks were attributed to pork; in both Salmonella was identified as the etiology. The first, in 2013, involved 14 patients from five states; the specific type or brand of pork was not identified. The other, in 2015, involved 192 patients from five states, $184(96 \%)$ of whom lived in Washington. The source of contamination was a pork slaughter establishment in Washington [5].

\section{Etiology of outbreaks}

A confirmed etiology was reported for 163 of 288 (57\%) pork-associated outbreaks during 1998-2015; in five $(2 \%)$ of these outbreaks, there were multiple confirmed etiologies. A suspected etiology was reported for an additional $60(21 \%)$ pork-related outbreaks, and 65 (23\%) had no etiology reported. During 1998-2001, 38 of $83(46 \%)$ outbreaks were reported with a confirmed etiology. During 2012-2016, 39 of 52 $(75 \%)$ outbreaks were reported with a confirmed etiology. Outbreaks with a confirmed etiology had a median of 16 (range 2-88) illnesses per outbreak, whereas outbreaks with unknown or suspected etiology had a median of 8 (range 2-33) illnesses per outbreak (Table 1).

Salmonella was the most commonly confirmed etiology ( 72 of $163,44 \%)$. The frequency of pork-related outbreaks with Salmonella as the confirmed etiology increased from an average of two per year (11\%) during 1998-2001 to an average of six per year during 20122015 (46\%) (Fig. 3). A single Salmonella serotype was 
Table 1. Characteristics of outbreaks attributed to pork, Foodborne Diseases Outbreak Surveillance System, 19982015

\begin{tabular}{|c|c|c|c|c|}
\hline & $\begin{array}{l}\text { Outbreaks, } \\
\text { no. }\end{array}$ & $\begin{array}{l}\text { Illnesses, } \\
\text { no. }\end{array}$ & $\begin{array}{l}\text { Illnesses per outbreak, median no. } \\
\text { (range) }\end{array}$ & $\begin{array}{l}\text { Hospitalizations, } \\
\text { no. }\end{array}$ \\
\hline Total & 288 & 6372 & $12(2-333)$ & 443 \\
\hline \multicolumn{5}{|l|}{ Pathogen } \\
\hline Salmonella & 72 & 2215 & $15 \cdot 5(3-333)$ & 276 \\
\hline $\begin{array}{l}\text { Staphylococcus aureus } \\
\text { enterotoxin }\end{array}$ & 37 & 1019 & $19(2-112)$ & 127 \\
\hline Clostridium perfringens & 20 & 681 & $20 \cdot 5(5-200)$ & 1 \\
\hline Norovirus & 14 & 340 & $17(4-94)$ & 2 \\
\hline Multiple confirmed pathogens & 5 & 132 & $18(8-68)$ & 2 \\
\hline Other confirmed pathogens ${ }^{\mathrm{a}}$ & 15 & 195 & $7(2-45)$ & 12 \\
\hline Suspected pathogen ${ }^{\mathrm{b}}$ & 60 & 969 & $9(2-88)$ & 13 \\
\hline Unknown & 65 & 821 & $7(2-75)$ & 10 \\
\hline \multicolumn{5}{|l|}{ Food type } \\
\hline Entrée & 134 & 2477 & $13(2-192)$ & 166 \\
\hline Ham & 60 & 1185 & $11(2-94)$ & 43 \\
\hline Barbecue & 58 & 1812 & $16 \cdot 5(2-283)$ & 134 \\
\hline Processed & 18 & 520 & $9(2-333)$ & 68 \\
\hline By-product ${ }^{\mathrm{c}}$ & 8 & 51 & $6 \cdot 5(3-12)$ & 16 \\
\hline Other & 10 & 327 & $16(2-200)$ & 16 \\
\hline \multicolumn{5}{|l|}{ Preparation location } \\
\hline Restaurant (including deli) & 99 & 2043 & $8(2-333)$ & 164 \\
\hline Private home & 60 & 909 & $10 \cdot 5(2-67)$ & 58 \\
\hline Multiple locations & 32 & 1121 & $19(3-192)$ & 106 \\
\hline Caterer or banquet facility & 35 & 984 & $26(4-100)$ & 31 \\
\hline Other commercial location & 24 & 336 & $9 \cdot 5(2-73)$ & 29 \\
\hline Unknown & 14 & 192 & $12(5-32)$ & 21 \\
\hline Other locations & 11 & 256 & $20(3-66)$ & 8 \\
\hline Religious facility & 7 & 434 & $25(18-200)$ & 21 \\
\hline Institution & 6 & 97 & $17 \cdot 5(3-29)$ & 5 \\
\hline \multicolumn{5}{|l|}{ Contributing factors ${ }^{\mathrm{d}}$} \\
\hline Any & 70 & 2464 & $18(2-333)$ & 174 \\
\hline Improper preparation & 58 & 2146 & $19 \cdot 5(2-333)$ & 168 \\
\hline Food handler hygiene & 15 & 650 & $18(3-333)$ & 57 \\
\hline Outside contamination & 19 & 774 & $17(2-333)$ & 104 \\
\hline Other contributing factors & 21 & 1175 & $18(3-333)$ & 94 \\
\hline
\end{tabular}

${ }^{\text {a }}$ Other confirmed pathogens, with number of outbreaks (illnesses), were: 8 (70) Yersinia enterocolitica, 2 (65) Bacillus cereus, 2 (9) Trichinella, 1 (27) Campylobacter, 1 (22) sapovirus, and 1 (2) Shigella.

${ }^{\mathrm{b}}$ Suspected pathogens, with number of outbreaks (illnesses), were: 20 (159) Staphylococcus aureus enterotoxin, 19 (423) Clostridium perfringens, 10 (215) norovirus, 4 (80) Salmonella, 2 (30) Bacillus cereus, 1 (3) Listeria monocytogenes, 2 (41) multiple pathogens, 1 (16) other bacterial pathogen, and 1 (2) other chemical etiology.

${ }^{c}$ By-products, with number of outbreaks (illnesses), were: 6 (40) chitterlings, 1 (4) pig's feet, and 1 (7) hog head cheese. Other food types with pork ingredients, with number of outbreaks (illnesses), were: 5 (57) sandwiches, 1 (9) soup, 1 (28) crispy pork, 1 (30) rutabaga, 1 (3) salsa, and 1 (200) pork with sauerkraut. Processed pork, with number of outbreaks (illnesses), were: 2 (18) bacon, 1 (12) blood sausage, 9 (419) sausage, 2 (32) pepperoni, 3 (24) meat on pizza, and 2 (15) canned products, such as SPAM $^{\circledR}$

${ }^{\mathrm{d}}$ Categories are not mutually exclusive; multiple contributing factors may be reported.

reported for 66 of $72(92 \%)$ Salmonella outbreaks, and the serotypes most frequently identified were Typhimurium (11, 17\%), Enteritidis (10, 15\%), I 4, [5],12:i:- (7, 11\%), Uganda (7, 11\%), Infantis $(6,9 \%)$, and Newport $(5,8 \%)$. All seven outbreaks of
Salmonella I 4,[5],12:i:- occurred in 2011 or later, and serotype I 4,[5],12:i:- accounted for $23 \%$ of singleserotype outbreaks of Salmonella during 2011-2015.

Staphylococcus aureus enterotoxin caused 37 (24\%) outbreaks. The frequency of $S$. aureus outbreaks 
Table 2. Characteristics of outbreaks attributed to pork during 1998-2001 and 2012-2015, Foodborne Diseases Outbreak Surveillance System

\begin{tabular}{|c|c|c|c|}
\hline & $\begin{array}{l}1998- \\
2001\end{array}$ & $\begin{array}{l}2012- \\
2015\end{array}$ & $P$-value \\
\hline Total & 83 & 52 & $0 \cdot 030$ \\
\hline \multicolumn{4}{|l|}{ Pathogen } \\
\hline Salmonella & 9 & 24 & $0 \cdot 082$ \\
\hline $\begin{array}{l}\text { Staphylococcus aureus } \\
\text { enterotoxin }\end{array}$ & 16 & 3 & $0 \cdot 014$ \\
\hline Clostridium perfringens & 5 & 6 & $0 \cdot 844$ \\
\hline Norovirus & 2 & 2 & $1 \cdot 000$ \\
\hline $\begin{array}{l}\text { Multiple confirmed } \\
\text { pathogens }\end{array}$ & 1 & 1 & $1 \cdot 000$ \\
\hline $\begin{array}{l}\text { Other confirmed } \\
\text { pathogens }{ }^{\mathrm{a}}\end{array}$ & 5 & 3 & 0.628 \\
\hline Suspected pathogen ${ }^{\mathrm{b}}$ & 13 & 11 & $0 \cdot 761$ \\
\hline Unknown & 32 & 2 & $<0 \cdot 001$ \\
\hline \multicolumn{4}{|l|}{ Food type } \\
\hline Entrée & 32 & 23 & $0 \cdot 278$ \\
\hline Ham & 30 & 5 & 0.009 \\
\hline Barbecue & 10 & 16 & $0 \cdot 356$ \\
\hline Processed & 5 & 3 & 0.595 \\
\hline By-product ${ }^{\mathrm{c}}$ & 4 & 1 & $0 \cdot 356$ \\
\hline Other & 2 & 2 & $1 \cdot 000$ \\
\hline \multicolumn{4}{|l|}{ Preparation location } \\
\hline Restaurant (including deli) & 32 & 14 & $0 \cdot 017$ \\
\hline Private home & 13 & 8 & $0 \cdot 550$ \\
\hline Multiple locations & 9 & 6 & $0 \cdot 560$ \\
\hline Caterer or banquet facility & 11 & 10 & $0 \cdot 859$ \\
\hline Other commercial location & 7 & 6 & $0 \cdot 834$ \\
\hline Unknown & 5 & 4 & $0 \cdot 780$ \\
\hline Other locations & 2 & 1 & 0.670 \\
\hline Religious facility & 1 & 2 & 0.537 \\
\hline Institution & 3 & 1 & $0 \cdot 390$ \\
\hline \multicolumn{4}{|l|}{ Contributing factors $^{\mathrm{d}}$} \\
\hline Any & 7 & 32 & $0 \cdot 046$ \\
\hline Improper preparation & 4 & 28 & $0 \cdot 025$ \\
\hline Food handler hygiene & 4 & 7 & $0 \cdot 589$ \\
\hline Outside contamination & 0 & 13 & $0 \cdot 014$ \\
\hline Other contributing factors & 2 & 8 & $0 \cdot 134$ \\
\hline
\end{tabular}

$\bar{a}$ Other confirmed pathogens include: Yersinia enterocolitica, Bacillus cereus, Trichinella, Campylobacter, sapovirus, and Shigella.

${ }^{\mathrm{b}}$ Suspected pathogens include: Staphylococcus aureus enterotoxin, Clostridium perfringens, norovirus, Salmonella, Bacillus cereus, Listeria monocytogenes, multiple pathogens, other bacterial pathogen, and other chemical etiology.

${ }^{\mathrm{c}}$ By-products include: chitterlings, pig's feet, and hog head cheese. Other food types with pork ingredients include: sandwiches, soup, crispy pork, rutabaga, salsa, and pork with sauerkraut. Processed pork includes: bacon, blood sausage, sausage, pepperoni, meat on pizza, and canned products, such as SPAM ${ }^{\circledR}$.

${ }^{\mathrm{d}}$ Categories are not mutually exclusive; multiple contributing factors may be reported. declined from four per year during 1998-2001 to $0 \cdot 75$ per year during 2012-2015 ( $P=0 \cdot 01)$ (Fig. 3). The next three most commonly confirmed pathogens were Clostridium perfringens (C. perfringens; 20, 12\%), norovirus $(14,9 \%)$, and $Y$. enterocolitica $(8,5 \%)$ (Table 1$)$.

Salmonella caused the most outbreak-associated illnesses $(2215,35 \%$ of illnesses in pork-associated outbreaks), followed by $S$. aureus $(1019,16 \%)$. The largest outbreak (333 illnesses) was caused by Salmonella I 4,[5],12:i:- and was linked to a restaurant in Nevada in 2013. Cooked pork sausage from the restaurant yielded the outbreak strain, but an investigation determined that the product likely became contaminated after cooking [6]. Pork-associated outbreaks due to Bacillus cereus (B. cereus) had the highest median number of illnesses (32.5), compared with outbreaks due to Salmonella (15.5) and S. aureus (19) (Table 1).

Salmonella and S. aureus were responsible for the largest numbers of hospitalizations ( $276,62 \%$ of total hospitalizations; $127,29 \%$, respectively) in pork-associated outbreaks (Table 1). Four patients died in outbreaks related to pork. Three deaths were associated with pork-associated Salmonella infections, two with an outbreak of serotype Enteritidis infections in 2009 attributed to pork sausage, one with an outbreak of serotype Typhimurium infections attributed to pork barbecue in 2015. The other death was associated with an outbreak of unknown etiology in 2003 attributed to barbecue pork ribs purchased from a restaurant and kept warm on a home grill for several hours. Salmonella and $S$. aureus were implicated in more outbreaks in the Summer and Fall (78\% and 67\%, respectively) than in the Winter and Spring (22\% and 33\%, respectively), while the opposite was true for norovirus (31\% in Summer/Fall and 69\% in Winter/Spring). All eight $Y$. enterocolitica outbreaks occurred in the Fall and Winter $(8,100 \%)$.

\section{Pork types implicated}

The most common type of pork implicated was pork entrée (134 outbreaks, 47\%), followed by ham ( 60 , $21 \%$ ), barbecue pork $(58,20 \%)$, and processed pork $(18,6 \%)$ (Table 1). The number of outbreaks associated with ham decreased from eight per year during 1998 2001 , to one per year during 2012-2015 $(P<0 \cdot 01)$. Outbreaks associated with entrées decreased from eight to six per year, and outbreaks associated with barbecue increased from 2.5 to four per year during the same periods (Table 2). Outbreaks associated with 


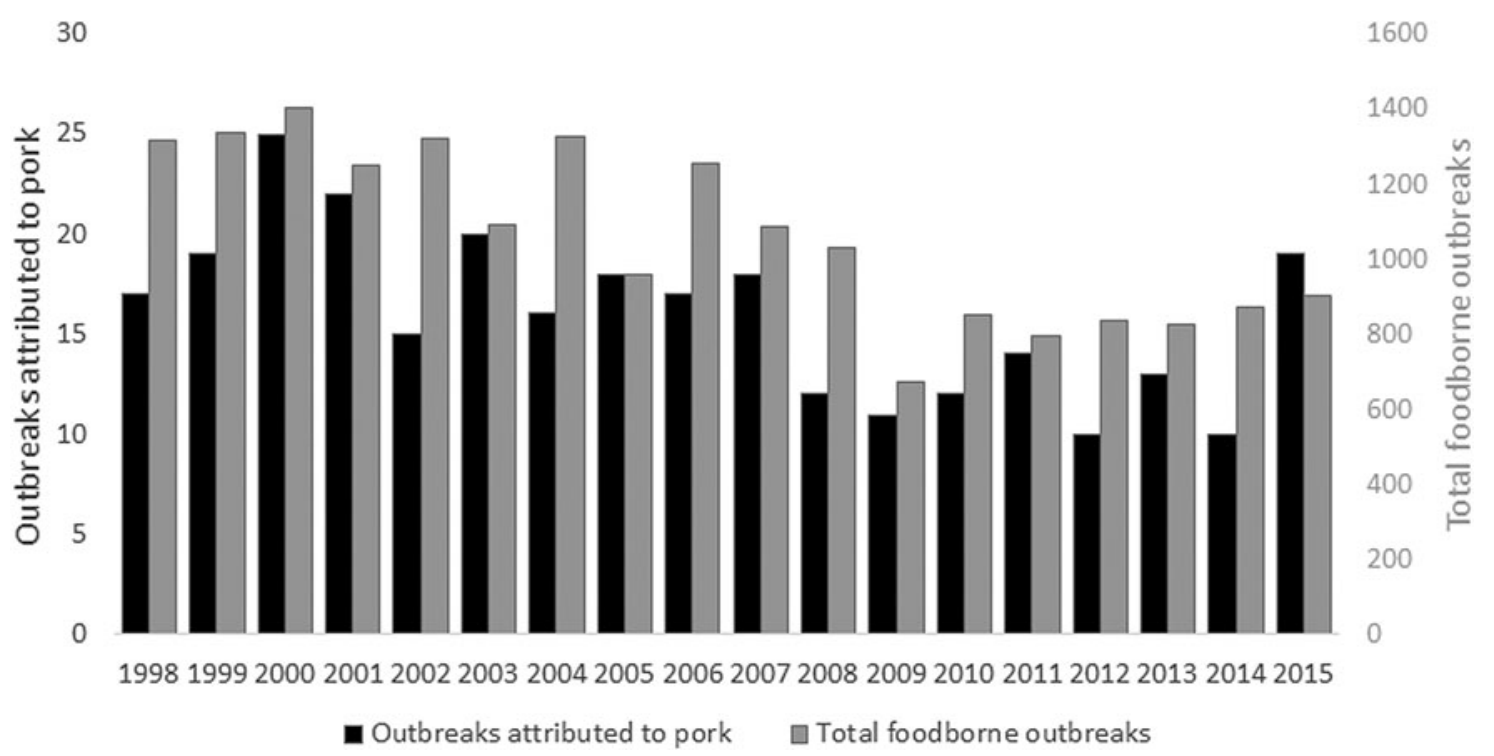

Fig. 1. Number of outbreaks attributed to pork and total number of foodborne outbreaks, Foodborne Diseases Outbreak Surveillance System, 1998-2015.

ham occurred most frequently in the spring $(19,32 \%)$ and least frequently in the summer $(12,20 \%)$, whereas outbreaks associated with entrées occurred most frequently in the summer $(49,37 \%)$ and least frequently in the spring $(22,16 \%)$.

\section{Preparation settings}

Implicated foods were prepared most often in restaurants (99 outbreaks, 34\%), but restaurant outbreaks decreased from an average of eight per year during 1998-2001 to 3.5 per year during 2012-2015 ( $P=$ $0 \cdot 02$ ) (Table 2). Implicated foods were also prepared at homes $(60,21 \%)$, catering or banquet facilities $(35,12 \%)$, religious facilities $(7,2 \%)$, and other commercial locations, such as grocery stores and festivals $(24,8 \%)$. Thirty-two (11\%) outbreaks were associated with food that had multiple locations of preparation. Eleven outbreaks were categorized as having other locations of preparation, which included community events, picnics, parks, and unlicensed commercial markets (Table 1).

Contaminated food prepared in a restaurant was most often a pork entrée $(46,47 \%)$ or barbecue $(24,24 \%)$. Pork entrée was also the most commonly contaminated food type prepared in private locations $(34,51 \%)$, at catering or banquet facilities $(16,46 \%)$, and in outbreaks with multiple preparation locations (13, 46\%). Ham was the most common food type in institutional settings (4, 67\%), and barbecue was the most common food type in other commercial settings $(9,38 \%)$.
The location of food preparation varied with the size of the outbreak. The median (range) number of illnesses per outbreak was 8 (2-333) for restaurants, 26 (4-100) for catering and banquet facilities, 9.5 (273) for other commercial locations, and 10.5 (2-67) for private homes (Table 1).

\section{Contributing factors}

At least one contributing factor was identified for 70 (24\%) of outbreaks (Table 1). A contributing factor was reported for $6 \%$ of outbreaks that occurred during 1998-2001 and for 58\% outbreaks during 2012-2015 (Table 2). One or more improper food preparation techniques were cited as a contributing factor for 58 $(20 \%)$ outbreaks. Contamination due to poor food handler hygiene was cited as a contributing factor in $15(5 \%)$ outbreaks, nine of which also cited improper food preparation. Contamination related to factors outside of the location of preparation was cited as a contributing factor in $19(7 \%)$ outbreaks, 17 of which also cited improper food preparation. Two $(<1 \%)$ outbreaks cited all three categories of contributing factors.

\section{DISCUSSION}

Our analyses are the first to summarize outbreaks attributed to pork in the United States. The overall decline in the annual number of outbreaks attributed to pork since 1998 is consistent with the decrease in 


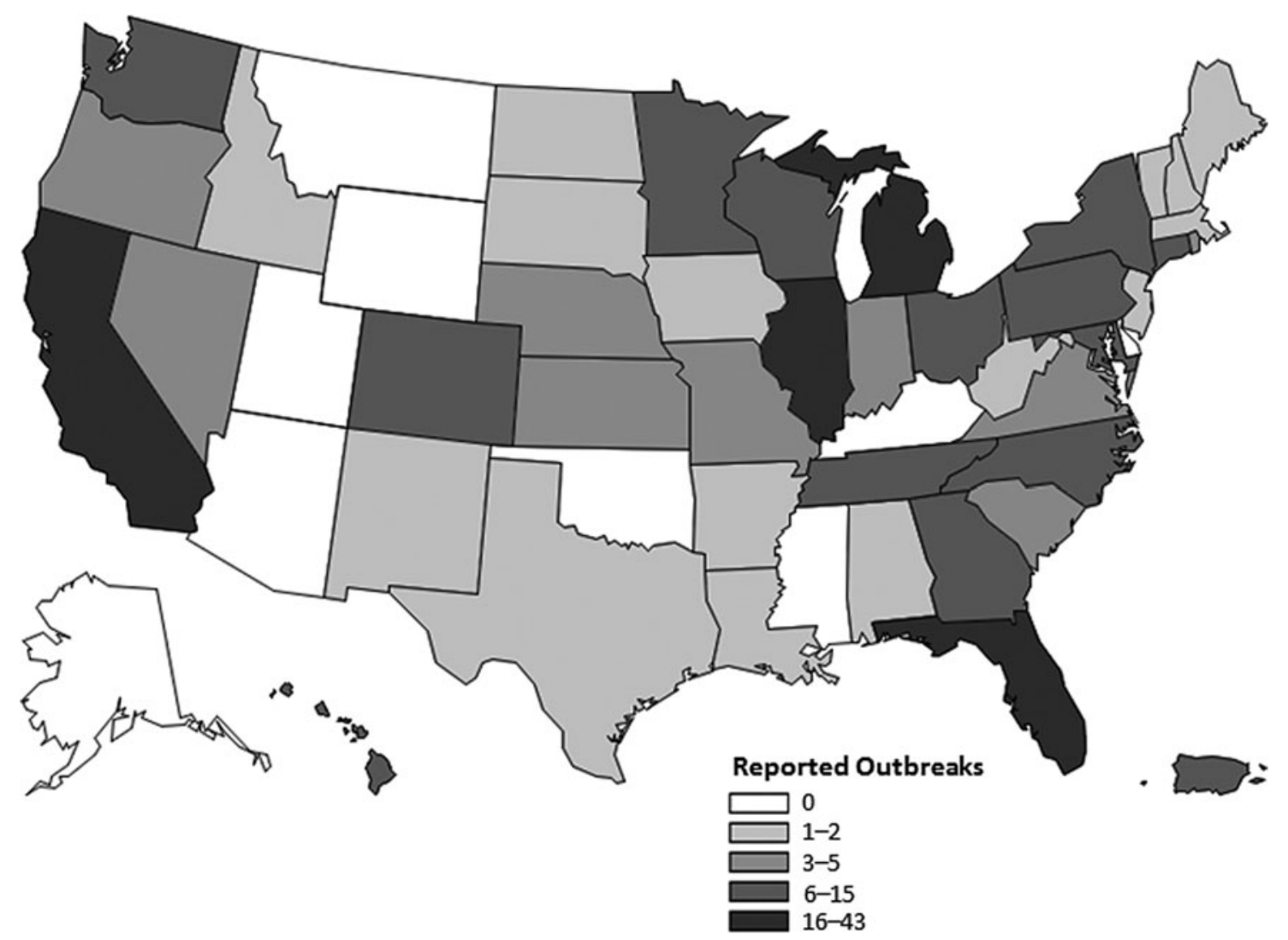

Fig. 2. Number of outbreaks attributed to pork with a single state of exposure, by state, Foodborne Disease Outbreak Surveillance System, 1998-2015.

total reported foodborne outbreaks during this time. It does not appear to be attributed to decreased consumption of pork. However, a substantial and increasing number of illnesses are associated with these outbreaks each year. Our analyses show that since 1998, Salmonella, especially serotype I 4,[5],12:i:-, has emerged as the most frequent etiology of pork-associated outbreaks, whereas pork-related outbreaks caused by $S$. aureus enterotoxin and $Y$. enterocolitica have declined.

The emergence of Salmonella I 4,[5],12:i:- in particular as a prominent etiology of pork outbreaks is especially concerning because this pathogen is often multidrug resistant $[5,23]$. Salmonella is found in the intestinal tracts of vertebrates and in environmental reservoirs, and can survive on foods and in processing environments [24]. Declines in outbreaks attributed to pork and the total reported foodborne outbreaks during this time period, without a related decrease in outbreaks of salmonellosis attributed to pork, suggest that the increase in outbreaks caused by Salmonella is a true increase, rather than due to improvements in outbreak detection and attribution.
The United Kingdom and the European Union have also documented a marked increase in Salmonella I 4,[5],12:i:- in humans and pork, mostly over the past 15 years [25]. Additional Salmonella control efforts are necessary during pork production to reduce pork-associated outbreaks of salmonellosis, and further research is needed to identify factors associated with the emergence of multidrug resistant I 4,[5],12: i:- in the United States.

Efforts to reduce Salmonella infections due to pork have focused on various facility and product testing programs, as well as regulatory policies on Salmonella as an adulterant on food. In 1998, the Food Safety and Inspection Service (FSIS) set a performance standard that no more than $8.7 \%$ of samples from swine carcasses at slaughter facilities should be positive for Salmonella [26]. By 2011, the data showed that market swine slaughter establishments had achieved Salmonella-positive rates at well below the standard $(2 \cdot 6 \%$ in $2008,2 \cdot 3 \%$ in $2009,2 \cdot 4 \%$ in 2010 , and $3 \cdot 3 \%$ in 2011) and FSIS suspended sampling to re-direct resources [27]. While FSIS has not generally considered Salmonella to be an adulterant of raw pork, in 2012 FSIS established a policy 


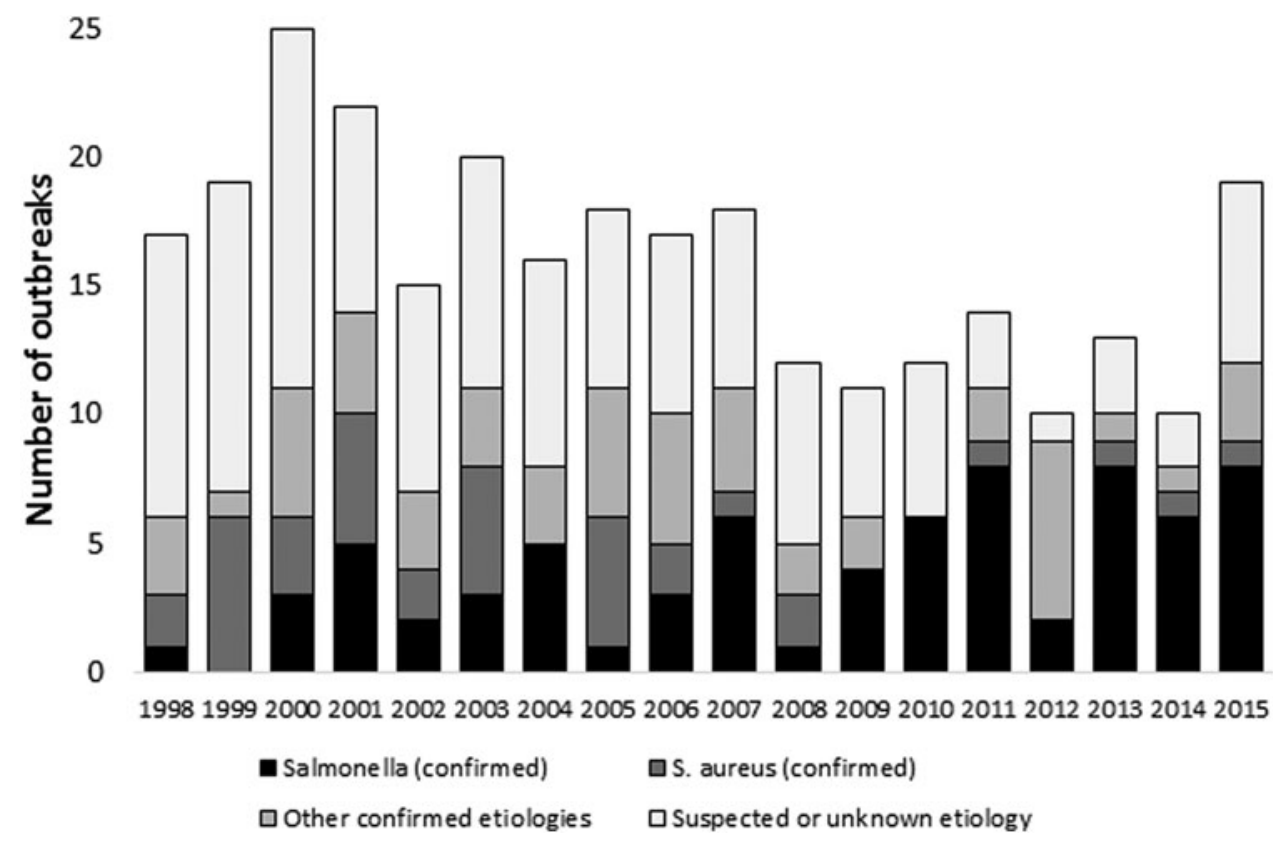

Fig. 3. Outbreaks attributed to pork with confirmed, suspected, and unknown etiology, Foodborne Disease Outbreak Surveillance System, 1998-2015.

that Salmonella on raw meat and poultry could be considered to be an adulterant in select situations, such as human illnesses linked to a specific product [28]. Food identified as adulterated is considered unfit for human consumption and must be recalled. The Food and Drug Administration's National Antimicrobial Resistance Monitoring System (NARMS) retail meat surveillance program, which obtains pork chops at retail establishments, is another source of data on contamination of pork products. During 2002-2014, Salmonella were detected in $1 \cdot 2 \%$ (range by year: $0 \cdot 6-2 \cdot 1 \%$ ) of pork chops sampled [29-31].

In 2013, in response to the lack of progress in reducing human salmonellosis, FSIS developed a Salmonella Action Plan that included efforts targeted toward determining whether FSIS-regulated pork products are contaminated with Salmonella and, if so, approaches to reduce that contamination [32]. In 2015, FSIS launched a Raw Pork Products Exploratory Sampling Project and detected Salmonella in $16.7 \%$ of pork product samples, including ground pork which may be more likely to yield Salmonella than swine carcass swabs or cuts of meat such as pork chops [33]. FSIS continued the sampling program in 2016 and 2017 and plans to use the results to inform policy options that could include the development of new Salmonella performance standards for pork [32, 34].

In the published literature, country-level evidence for successful Salmonella control in pork is limited.
Finland maintains an annual prevalence of Salmonella in meat, including pork, below $1 \%$ through a combination of industry-led voluntary measures and regulations. Control measures include restrictions on contaminated feed, a robust sampling program for all meats, testing of all meat imports, and, when samples test positive, sale restrictions and disinfection procedures [35]. Denmark's Salmonella surveillance and control efforts have shifted from pre-harvest initiatives to improved hygiene in slaughterhouses because they found that post-harvest control strategies are more cost-effective. They allow slaughterhouses to determine the most appropriate method to control Salmonella as long as they meet the targets for Salmonella control, $<1 \%$ of meat-juice samples from finisher pigs at slaughter [36].

Most pork-related outbreaks occurred within the boundaries of a single state. Two multistate outbreaks were identified, both of which were caused by Salmonella. The relatively few multistate outbreaks may in part be explained by improvements in the supply chain that minimize pathogen contamination and proliferation until later gaps in safe handling, such as undercooking or cross-contamination, create localized opportunities for pathogen proliferation. Reporting of contributing factors has increased likely due to improved outbreak response, laboratory capacity, and improved reporting. Continued attention to environmental assessments and analysis of contributing 
factors may provide evidence to guide further improvements in food safety [37]. However, it is possible that the low number of multistate outbreaks is due to incomplete detection of widely distributed outbreaks (e.g. inability to distinguish illnesses due to widely distributed pork products from background illnesses) or inadequate ability to implicate pork as the contaminated food in widely dispersed outbreaks. All multistate outbreaks due to pork were outbreaks of Salmonella infections. This may be due to the fact that Salmonella was one of the first pathogens to be tracked by PulseNet USA, the national molecular subtyping network for foodborne disease surveillance. PulseNet has collected data on Salmonella infections since 1994, which has likely made it possible to identify Salmonella outbreaks that may have previously gone undetected [38].

Outbreaks caused by $S$. aureus enterotoxin declined, especially those linked to ham. Staphylococci exist in the environment (air, dust, on surfaces) as well as in humans and animals, and are killed by cooking. However, inadequate temperature control of food allows the bacteria to multiply quickly, resulting in production of enterotoxin, which is heat stable [24]. The reason for the decline in $S$. aureus outbreaks associated with ham is not known. One possibility is that FSIS regulations published in 1999 related to cooking and holding temperatures in facilities producing ready-to-eat, large meat items had a role [39]. Adherence to recommended food preparation practices, including food handler hygiene and proper temperature controls, may have contributed to the decline of $S$. aureus outbreaks. It is also possible that barriers to laboratory testing for $S$. aureus or variations in enterotoxin production by strain contribute.

C. perfringens and norovirus were, respectively, the third and fourth most common pathogens that caused pork outbreaks. C. perfringens spores are not killed by cooking, and the bacteria may proliferate if cooked food is not refrigerated or kept at an appropriate temperature. Outbreaks of $C$. perfringens are often associated with settings in which cooked foods are maintained at warm or ambient temperature for long periods [24]. Norovirus is typically introduced by infected food handlers [40].

A limitation of these analyses is that they likely underestimate the number of illnesses associated with pork outbreaks because some outbreaks are never detected or a food vehicle is not identified. In fact, of the estimated 525000 foodborne illnesses attributed to pork each year, fewer than $0 \cdot 1 \%$ are associated with reported outbreaks [4]. The increase in proportion of outbreaks with laboratory-confirmed etiology is likely due to improvements in laboratory capacity, outbreak investigation, and reporting. The number of illnesses in outbreaks with a confirmed etiology was double the median number of illnesses in outbreaks with unknown or suspected etiologies, suggesting that smaller outbreaks are less likely to have a confirmed etiology. Likewise, it may be more challenging to identify a food vehicle for small outbreaks. The extent of underestimation may vary by jurisdiction and time. It is unclear whether geographic variation in the number of outbreaks attributed to pork is due to differences in exposures, outbreak detection and investigation, or other factors. It is also difficult to determine whether changes over time are primarily due to improved food safety practices, changes in outbreak detection, attribution, and reporting, or changes in dietary patterns. Few outbreaks in this dataset from FDOSS include data on antimicrobial resistance, limiting our ability to assess patterns of resistance in these analyses.

A substantial burden of illness is attributed to pork, and outbreaks can help identify where improvements are needed. Outbreaks attributed to pork should continue to be monitored to assess whether the higher number of outbreaks reported in 2015 compared with other recent years reflects a concerning trend or year-to-year variation, and to inform recommendations for controlling Salmonella, especially for limiting further spread of the often-resistant serotype I 4,[5],12: i:-. The emergence of an antibiotic-resistant strain of Salmonella in outbreaks associated with pork is a concern. FSIS is working to monitor and reduce Salmonella contamination on pork products. Although illness can often be prevented by cooking and preventing cross-contamination at restaurants and in homes, interventions further back on the farm-to-table chain, such as Salmonella control at slaughter facilities, are most likely to be effective. Additional efforts are necessary to reduce outbreaks associated with pork products, including improving pathogen control during processing, adhering to recommended preparation and storage practices, and changes in food safety policies for pork.

\section{ACKNOWLEDGEMENTS}

The authors thank Patricia M. Griffin, Samuel J. Crowe, Tim B. Mohr, and David Goldman for reviewing drafts of this manuscript and providing 
helpful feedback. The authors also thank the local, state, and federal public health professionals who participated in the surveillance and outbreak investigations that made these analyses possible, as well as CDC's National Outbreak Reporting System (NORS) team that provided access to this data. This research received no specific grant from any funding agency, commercial, or non-for-profit sectors. The findings and conclusions in this report are those of the authors and do not necessarily represent the views of the Centers for Disease Control and Prevention or the Food Safety and Inspection Service.

\section{DECLARATION OF INTEREST}

None.

\section{REFERENCES}

1. Djurković-Djaković O, et al. Pork as a source of human parasitic infection. Clinical Microbiology and Infection 2013; 19: 586-594.

2. Lassok B, Tenhagen B-A. From pig to pork: methicillinresistant Staphylococcus aureus in the pork production chain. Journal of Food Protection 2013; 76: 1095-1108.

3. Ojha S, Kostrzynska M. Approaches for reducing Salmonella in pork production. Journal of Food Protection 2007; 70: 2676-2694.

4. Painter JA, et al. Attribution of foodborne illnesses, hospitalizations, and deaths to food commodities by using outbreak data, United States, 1998-2008. Emerging Infectious Diseases 2013; 19: 407-415.

5. Kawakami VM, et al. Notes from the field: outbreak of multidrug-resistant Salmonella infections linked to pork - Washington, 2015. Morbidity and Mortality Weekly Report 2016; 65: 379-381.

6. Linh N. Salmonella I 4,5,12:i:- Gastroenteritis Outbreak Among Patrons of Firefly on Paradise Restaurant - Las Vegas, Nevada, 2013. (http://southernnevadahealthdistrict. org/download/stats-reports/firefly-final-report-011314.pdf). Accessed 6 September 2017.

7. Huovinen E, et al. Symptoms and sources of Yersinia enterocolitica-infection: a case-control study. $B M C$ Infectious Diseases 2010; 10: 122.

8. Roy SL, Lopez AS, Schantz PM. Trichinellosis surveillance - United States, 1997-2001. Morbidity and Mortality Weekly Report Surveillance Summaries (Washington, DC: 2002) 2003; 52: 1-8.

9. Gottstein B, Pozio E, Nockler K. Epidemiology, diagnosis, treatment, and control of trichinellosis. Clinical Microbiology Reviews 2009; 22: 127-145.

10. Wilson NO, et al. Trichinellosis surveillance - United States, 2008-2012. Morbidity and Mortality Weekly Report: Surveillance Summaries (Washington, DC: 2002) 2015; 64: 1-8.

11. Centers for Disease Control and Prevention. Yersinia enterocolitica infections during the holidays in black families - Georgia. Morbidity and Mortality Weekly Report: Topics in Minority Health 1990; 39: 819-820.

12. Jones T, et al. From pig to pacifier: chitterling-associated yersiniosis outbreak among black infants. Emerging Infectious Diseases 2003; 9: 1007-1009.

13. Ong KL, et al. Changing epidemiology of Yersinia enterocolitica infections: markedly decreased rates in young black children, Foodborne Diseases Active Surveillance Network (FoodNet), 1996-2009. Clinical Infectious Diseases 2012; 54(Suppl 5): S385-S390.

14. Ray SM, et al. Population-based surveillance for Yersinia enterocolitica infections in FoodNet sites, 1996-1999: higher risk of disease in infants and minority populations. Clinical Infectious Diseases 2004; 38(Suppl 3): S181-S189.

15. Wesley I, Bhaduri S, Bush E. Prevalence of Yersinia enterocolitica in market weight hogs in the United States. Journal of Food Protection 2008; 71: 1162-1168.

16. Centers for Disease Control and Prevention. Foodborne Outbreak Tracking and Reporting (http://www.cdc.gov/ foodsafety/fdoss/). Accessed 24 June 2016.

17. Centers for Disease Control and Prevention. National Outbreak Reporting System (NORS) Guidance Document (http://www.cdc.gov/nors/pdf/NORS-Guidance_FINAL 508c.pdf). Accessed 22 January 2016.

18. United States Department of Agriculture. Livestock and meat domestic data: livestock, dairy, and poultry outlook (http://www.ers.usda.gov/data-products/livestockmeat-domestic-data.aspx\#26105). Accessed 28 June 2016.

19. United States Department of Agriculture. Food Availability (Per Capita) Data System (http://www.ers.usda.gov/dataproducts/food-availability-(per-capita)-data-system/ food-availability-documentation.aspx). Accessed 9/2/2016.

20. Centers for Disease Control and Prevention. Guide to Confirming an Etiology in Foodborne Disease Outbreak (http://www.cdc.gov/foodsafety/outbreaks/investigatingoutbreaks/confirming_diagnosis.html). Accessed 17 March 2016.

21. Bryan FL, Guzewich JJ, Todd ECD. Surveillance of foodborne disease III. Summary and presentation of data on vehicles and contributory factors; their value and limitations. Journal of Food Protection 1997; 60: 701-714.

22. Gould LH, et al. Contributing factors in restaurant-associated foodborne disease outbreaks, FoodNet sites, 2006 and 2007. Journal of Food Protection 2013; 76: 1824-1828.

23. Centers for Disease Control and Prevention. National Antimicrobial Resistance Monitoring System (NARMS) 2014 Human Isolates Surveillance Report (https://www. cdc.gov/narms/pdf/2014-annual-report-narms-508c.pdf). Accessed 19 December 2016.

24. Food and Drug Administration. The Bad Bug Book: Foodborne Pathogenic Microorganisms and Natural Toxins Handbook, 2nd edn (https://www.fda.gov/downloads/Food/FoodborneIllnessContaminants/UCM297627. pdf). Accessed 6 September 2017.

25. Hopkins KL, et al. Multiresistant Salmonella enterica 4, [5],12:I:- in Europe: a new pandemic strain? Eurosurveillance 2010; 15: 19580. 
26. United States Department of Agriculture. Pathogen reduction; Hazard Analysis and Critical Control Point (HACCP) systems; final rule. Federal Register 1996; 61: 38805-38989.

27. United States Department of Agriculture FSIS. Progress Report on Salmonella and Campylobacter Testing of Raw Meat and Poultry Products, 1998-2013, 2013 (https://www.fsis.usda.gov/wps/wcm/connect/885647f42568-48bf-ae5c-4a0d8279f435/Progress-Report-SalmonellaCampylobacter-CY2013.pdf?MOD=AJPERES). Accessed 6 September 2017.

28. United States Department of Agriculture. HACCP plan reassessment for not-ready-to-eat comminuted poultry products and related agency verification procedures. Federal Register 2012; 77: 72686-72691.

29. Food and Drug Administration. National Antimicrobial Resistance Monitoring System 2012 Retail Meat Report (http://www.fda.gov/downloads/AnimalVeterinary/Safety Health/AntimicrobialResistance/NationalAntimicrobial ResistanceMonitoringSystem/UCM442212.pdf). Accessed 7 December 2016.

30. U. S. Food and Drug Administration. NARMS integrated report: 2014 (http://www.fda.gov/downloads/ AnimalVeterinary/SafetyHealth/AntimicrobialResistance/ NationalAntimicrobialResistanceMonitoringSystem/ UCM528861.pdf). Accessed 19 December 2016.

31. U. S. Food and Drug Administration. NARMS integrated report: 2012-2013 (http://www.fda.gov/downloads/ AnimalVeterinary/SafetyHealth/AntimicrobialResistance/ NationalAntimicrobialResistanceMonitoringSystem/ UCM453398.pdf). Accessed 19 December 2016.

32. United States Department of Agriculture. Salmonella Action Plan (http://www.fsis.usda.gov/wps/wcm/connect/ aae911af-f918-4fe1-bc42-7b957b2e942a/SAP-120413. pdf?MOD=AJPERES). Accessed 28 January 2016.
33. United States Department of Agriculture. Sampling results for FSIS regulated products (https://www.fsis. usda.gov/wps/portal/fsis/topics/data-collection-andreports/microbiology/sampling-project-results/results). Accessed 20 December 2016.

34. United States Department of Agriculture. Changes to the Salmonella and Campylobacter verification testing program: proposed performance standards for Salmonella and Campylobacter in not-ready-to-eat comminuted chicken and Turkey products and raw chicken parts and related agency verification procedures and other changes to agency sampling. Federal Register 2015; 80: 12618-12620.

35. Maijala R, et al. The efficiency of the Finnish Salmonella Control Programme. Food Control 2005; 16: 669-675.

36. Albana L, et al. Salmonella surveillance and control for finisher pigs and pork in Denmark - a case study. Food Research International 2012; 45: 656-665.

37. Brown LG, et al. Outbreak characteristics associated with identification of contributing factors to foodborne illness outbreaks. Epidemiology and Infection 2017; 145: 2254-2262.

38. Scharff RL, et al. An economic evaluation of PulseNet: a network for foodborne disease surveillance. American Journal of Preventive Medicine 2016; 50: S66-S73.

39. United States Department of Agriculture. Compliance Guidelines For Meeting Lethality Performance Standards For Certain Meat And Poultry Products (http://www.fsis. usda.gov/wps/wcm/connect/212e40b3-b59d-43aa-882ee5431ea7035f/95-033F-Appendix-A.pdf?MOD=AJPERES). Accessed 22 July 2016.

40. Hall AJ, et al. Vital signs: foodborne norovirus outbreaks - United States, 2009-2012. Morbidity and Mortality Weekly Report 2014; 63: 491-495. 